\title{
CONSERVAÇÃO AMBIENTAL: UMA PROPOSTA DE INTERVENÇÃO E INTERDISCIPLINARIDADE EM ESCOLA DE FLORIANO-PI
}

\section{ENVIRONMENTAL CONSERVATION: A PROPOSAL FOR INTERVENTION AND INTERDISCIPLINARITY IN SCHOOL OF FLORIANO-PI}

\author{
Marciléia de Sousa Batista ${ }^{1}$; Welton de Sousa Batista ${ }^{2}$; Wanderson Mateus Bispo da Silva ${ }^{3}$; \\ José Da Guia da Conceição Ferreira ${ }^{4}$; Iara Maria Cavalcante Nolêto ${ }^{5}$
}

\section{RESUMO}

O meio ambiente encontra-se em um estado caótico, em função das ações inconsequentes do homem, tais como: queimadas, desmatamentos, poluição do ar, dos rios e extinção da fauna e da flora. Esses problemas estão se agravando no decorrer do tempo e se não forem adotadas as providências cabíveis, em um futuro não longínquo o meio ambiente padecerá de graves consequências, dentre elas: a falta de água, o aumento da temperatura média global, doenças respiratórias, contaminação do solo, extinção de animais, entre inúmeros outros malefícios. Dessa forma, o presente projeto almejou a promoção da conservação ambiental, a sustentabilidade, bem como a adoção de medidas preventivas em prol de minimizar os impactos ambientais, na luta incessante por um mundo mais sustentável. Buscou-se apresentar situações-problemas que possam levantar questionamentos nos alunos, incentivando-os a assumir uma consciência ambiental, buscando soluções e alternativas sustentáveis para resolução dos problemas ambientais; Estimular e despertar nestes alunos o senso de responsabilidade com o meio ambiente, assim como mudanças de atitudes que sejam prejudiciais à natureza; Expor dados com o tempo de decomposição de alguns materiais que prejudicam o meio-ambiente, como também um vídeo de como se realiza o processo de preparação do solo para a plantação de mudas para reflorestamento. Através deste projeto, foi possível identificar a falta de informações necessárias, que tendem a ser trabalhadas de forma mais intensa no ambiente escolar, portanto, optou-se por proporcionar momentos como este, para debater sobre o tema em tela, reforçar a sua importância e aprofundar os prévios conhecimentos desses alunos. O projeto supracitado foi realizado com alunos do $2^{\circ}$ e $3^{\circ}$ ano do curso técnico em Farmácia da Instituição de ensino Centro Estadual de Ensino Profissionalizante Calisto Lobo-CEEP em Floriano-PI, com o intuito de promover, além de uma relevante intervenção, a ideia de interdisciplinaridade.

Palavras-Chave: Conservação Ambiental, Meio-ambiente, Sustentabilidade, Interdisciplinaridade.

\begin{abstract}
The environment is in a chaotic state, due to the inconsequential actions of man, such as: burning, deforestation, pollution of the air, rivers and extinction of fauna and flora. These problems are worsening over time and, if they have not been adopted, in the not-too-distant future they have suffered serious consequences, such as lack of water, rising global average temperature, respiratory diseases, soil contamination, extinction of animals, among innumerable other ills. In this way, the present project aimed at promoting environmental

\footnotetext{
${ }^{1}$ Licenciatura em Ciências Biológicas, Instituto Federal do Piauí-IFPI, marcileiabatista98@gmail.com

${ }^{2}$ Licenciatura em Matemática, Instituto Federal do Piauí-IFPI, weltonsousa08@gmail.com

${ }^{3}$ Licenciatura em Ciência Biológicas, Instituto Federal do Piauí-IFPI, wandersonmatheus42@gmail.com

${ }^{4}$ Licenciatura em Ciências Biológicas, Instituto Federal do Piauí-IFPI, josedaguia30@outlook.com

${ }^{5}$ Professora Especialista do Instituto Federal do Piauí-IFPI, iaranoleto@ifpi.edu.br
} 
conservation, sustainability, as well as the adoption of preventive measures to minimize environmental impacts in the incessant struggle for a more sustainable world. It was tried to present situations problems that can raise questions in the students, encouraging them to assume an environmental conscience, searching for solutions and sustainable alternatives to solve the environmental problems; Stimulate and awaken in these students the sense of responsibility towards the environment, as well as changes in attitudes that are harmful to nature; Expose data with the time of decomposition of some materials that harm the environment, as well as a video of how the process of preparation of the soil for the planting of seedlings for reforestation is carried out.Through this project, it was possible to identify the lack of necessary information, which tend to be worked more intensely in the school environment, therefore, it was decided to provide moments like this, to debate on the subject on screen, to reinforce its importance and students' previous knowledge. The aforementioned project was carried out with students of the 2nd and 3rd year of the technical course in Farmacy of the Educational Institution of the State Center of Vocational Education Calisto Lobo-CEEP in Floriano-PI, in order to promote, besides a relevant intervention, the idea of interdisciplinarity.

Keywords: Environmental Conservation, Environment, Sustainability, Interdisciplinarity.

\section{INTRODUÇÃO}

O ser humano, enquanto individuo de um meio, desempenha um papel muito importante para a manutenção da vida na terra, cumprindo algumas condições primordiais para a garantia da harmonia, ordem dentre outros, e é por meio de alguns princípios que o homem, fazendo parte de uma sociedade bem estruturada, pode ter a proteção de direitos igualitários para todos (SARLET, 2018). A espécie humana é, então, tida como uma espécie mais evoluída dente os outros seres, dotados de consciência, senso crítico, detentor de pensar no coletivo sem abrir mão do seu individualismo que, caracteristicamente, forma a sua personalidade, e inúmeras habilidades que tornam cada ser único. Mas em plena era tecnológica, após passarmos por longos processos de adaptações, nota-se que o homem no decorrer do tempo foi adquirindo um potencial enorme para preservar a vida na terra, e também para destruí-la, diminuindo cada vez mais a qualidade de vida (JACOBI, 1999).

Atualmente, o índice de poluição no meio em que vivemos apresenta uma enorme proporção, pois se percebe que a cada ano essas taxas de poluição vêm aumentando gradativamente, mas em dimensões preocupantes, o que tem gerado efeitos severos no planeta, como o efeito estufa por exemplo. O efeito estufa é ocasionado pela emissão de gases poluentes na atmosfera e que, posteriormente, tem uma íntima relação com o aquecimento global, condições ocasionadas também pela desigualdade entre os povos (ABRAMOVAY, 2018). Não é necessário ir muito longe para constatar essa situação de calamidade, que tende a aumentar cada vez mais se não forem tomadas às devidas providências. Todos estão 
expostos às possíveis consequências dos próprios atos, sobretudo para o meio ambiente que é o principal alvo. As enchentes, inundações, mudanças drásticas no clima, vegetação, relevo, trazem prejuízos e sequelas irreversíveis, que mesmo sabendo disso, o homem age sem refletir sobre as consequências. $\mathrm{O}$ homem não está livre de tudo que causa alterações ambientais e mudanças climáticas drásticas que trazem um leque imenso de doenças e que são sensíveis às alterações do meio ambiente, podendo variar de acordo com a região (DUARTE, 2017).

Os problemas ambientais afetam todas as formas de vida na terra, que está sendo devastada lentamente por mudanças climáticas que estão ocorrendo em ritmo acelerado, parece confuso, mas por não conservar o meio ambiente, o ser humano corre o risco de causar sua própria extinção. O cuidado com os recursos naturais é primordial para que no futuro eles não venham a se esgotar, percebe-se que alguns países onde anos atrás apresentavam temperaturas consideradas baixas, hoje sofrem com temperaturas elevadas (VENTURA et al., 2014).

O Brasil é conhecido mundialmente por apresentar uma vasta cultura, uma diversidade biológica muito grande, com ecossistemas variados, climas diferentes entre as regiões e também pelas imensas áreas florestais que temos aqui, os índices de desmatamento são quase que proporcionais a esta extensão. Isso tem levado os países mais desenvolvidos a olharem com mais apreensão para as terras brasileiras, pois percebem a importância das florestas ou até mesmo a falta delas nas mudanças de temperatura e aquecimento global. $\mathrm{O}$ Brasil é famoso ainda mais, por ter recebido o título de país que mais vem desmatando ano após ano, tendo grandes áreas desmatadas em seu território (BENEVIDES; ALMEIDA, 2015).

A degradação ambiental está presente intensamente no Piauí. Percebe-se uma alteração drástica no clima em consequência do aquecimento global, que vem se agravando em função da emissão do $\mathrm{CO}^{2}$ na atmosfera. Os rios sofrem com a poluição e falta de saneamento básico nos centros urbanos, e com o desmatamento em fluxo crescente o meio ambiente não consegue se recuperar com a mesma velocidade (SILVA; BARROS, 2016).

A situação citada anteriormente se encaixa perfeitamente no contexto em que o município de Floriano-PI, se encontra. Poucas são as iniciativas tomadas pelos governantes em prol da reversão desse status caótico em que o meio ambiente está inserido atualmente. Todavia, algumas escolas já estão se mobilizando, com o intuito de promover a conscientização da sociedade em relação à conservação ambiental.

Os objetivos deste projeto foram: incentivar os discentes a assumir uma consciência ambiental, buscando soluções e alternativas sustentáveis para resolução dos problemas 
ambientais; estimular e despertar nesses alunos o senso de responsabilidade para com o meio ambiente, assim como mudanças de atitudes que sejam prejudiciais à natureza; expor dados com o tempo de decomposição de alguns materiais prejudiciais ao meio ambiente, utilizandose também de vídeos complementares, que exemplifiquem o processo de preparação do solo para reflorestamento.

\section{FUNDAMENTAÇÃO TEÓRICA}

Durante muito tempo a temática em torno do meio ambiente simplesmente foi ignorada, quase nunca se questionavam as ações do homem no ambiente em que vivia, nem tão pouco os possíveis efeitos para as gerações futuras, isso começou a mudar a partir do momento em que um aporte histórico passou a ser observado, onde se percebeu que as condições de vida vinham se modificando ano a ano, e que as ações individuais tinham impacto direto no coletivo. Isso levantou uma questão de ordem geral, a consciência de que é preciso mudar a sociedade em que vivemos, e tornarmo-nos indivíduos mais atentos às questões ambientais, para assim garantir a vida na terra. (DELUIZ; NOVICKI, 2018).

A preocupação com o meio ambiente se tornou universal porque a partir da realidade atual, percebeu-se que as fronteiras comuns não importavam, já que os efeitos atingiam todo o planeta. E hoje o meio ambiente é um assunto que vem despertando o interesse de todos, principalmente pelo temor dos efeitos causados pela ação do homem, que interferiu de forma indiscriminada no meio, promovendo degradação no ambiente (CAMPOS JUNIOR, 2002). Com isso, as autoridades internacionais competentes vêm impondo medidas a toda a comunidade, para que se diminuam os índices de emissão de poluentes, assim como o desmatamento das áreas florestais, e o cuidado com o lixo. Em menor escala cada indivíduo tem um papel muito importante nesse processo, o que ainda vem sendo negligenciada por muitas pessoas, a grande preocupação é então conscientizar a sociedade do problema para que as possíveis soluções possam ser tomadas (RIBEIRO; MARTINS, 1993).

Após a identificação dos problemas ambientais pelos quais o planeta vem passando, uma das maneiras mais eficientes de tratar disso com os jovens é por meio de abordagens no ambiente escolar, onde os alunos poderão ter uma ideia dos prejuízos que podem ser herdados pela falta de cuidado com o nosso planeta (GORNI et al., 2016). A conservação ambiental inserida nas disciplinas dá ao professor oportunidades de aproximar conhecimentos estudados à rotina dos alunos, podendo mostrá-los que pequenas ações podem ajudar na saúde do planeta, e dando uma chance de estar conscientizando a família através dos filhos que levarão a discussão para o ambiente familiar (CARVALHO, 2017). 
O professor para abordar a conservação ambiental, vai precisar decifrar a sociedade, atentando-se para aspectos de interpretação que lhe permitirão compreender de que modo as questões ambientais devem ser mostradas, elucidando possíveis dúvidas e questionamentos, como aponta Carvalho (2001):

\footnotetext{
[...] a busca dos sentidos da ação humana que estão na origem dos processos socioambientais parece sintetizar bem o cerne do fazer interpretativo em educação ambiental. Ao evidenciar os sentidos culturais e políticos em ação nos processos de interação sociedade-natureza, o educador seria um intérprete das percepções - que também são, por sua vez, interpretações sociais e históricas - mobilizadoras dos diversos interesses e intervenções humanas no meio ambiente. Bem ao contrário de uma visão objetiva, na qual interpretar o meio ambiente seria captá-lo em sua realidade factual, descrever suas leis, mecanismos e funcionamento, trata-se aqui de evidenciar os horizontes de sentido histórico-culturais que configuram as relações com o meio ambiente para uma determinada comunidade humana e num tempo específico (p.32).
}

$\mathrm{Na}$ conjectura atual percebe-se que as grandes indústrias privadas tem se apropriado cada vez mais dos recursos naturais, seguidos por um pensamento que visa o lucro advindo de uma sociedade capitalista, com uma produção acelerada e em ritmo crescente, sendo então os principais responsáveis pela atual situação ambiental, produzindo enormes quantidades de lixo oriundos da produção e consumo (ZANETI; SÁ, 2002).

Corroborando com os autores acima Sachs (1993) assegura que não se pode considerar a natureza um objeto da sociedade, pois ambas vivem em total sintonia, tempos respostas automáticas geradas pelos estímulos causados um pelo outro. A natureza não é uma abstração existente apenas para satisfazer a vontade do homem, ela responde quando é afetada, e esses efeitos são percebidos pelo homem em forma de catástrofes e desastres ambientais. Em uma sociedade saudável temos pessoas comprometidas com o bem estar geral de todos, buscando atender as necessidades de todos os indivíduos, sem prejudicar o direito das gerações futuras fazerem o mesmo.

\section{METODOLOGIA}

Este trabalho apresenta uma proposta de abordagem qualitativa e quantitativa, que buscou por meio da apresentação do projeto "Conservação Ambiental: um ato de amor" mostrar aos alunos de $2^{\circ} \mathrm{e} 3^{\circ}$ ano do curso Técnico de Farmácia na instituição de ensino Centro Estadual de Educação Profissional Calisto Lobo (CEEP), no Município de Floriano- PI, que os recursos disponíveis no planeta não são infinitos, e que enquanto membros do meio faz-se necessário contribuir à parte para que as gerações futuras também possam desfrutar destes recursos, pois 
se entende serem essas pequenas ações de hoje que irão contribuir para que todas as formas de vida tenham resguardadas o seu direito de "existir", considerando o pressuposto da sobrevivência e organização em sociedade, a manutenção da vida sem prejudicar as demais espécies e o planeta.

Através do projeto buscou-se investigar de que forma os alunos enxergavam o tema conservação ambiental, apresentando vários dados, estatísticas das capitais do país que apresentam maior índice de poluentes ao meio, com registros de fotografias locais da cidade em que residem com significativa presença de poluição, aproximando assim a temática abordada com a realidade dos mesmos e acercar-se do problema, para que tenham consciência da seriedade e urgência de tal assunto, também utilizou-se de vídeos em que revela o descuido do homem com a natureza e os recursos naturais, no intuito de assim causar uma postura reflexiva sobre a real situação do meio ambiente.

Como instrumento de coleta de dados foram aplicados questionários com questões abertas e fechadas, para assim avaliar a percepção dos alunos sobre a tematica em questão, um Estudo de Caso que contou com a participação de 27 alunos.Para extrair o máximo de informações a respeito da percepção dos alunos, decidiu-se transcrever os trechos de suas falas consideradas mais importantes, e identificando os alunos com a seguinte nomenclatura: aluno-01 ...aluno-27.

\section{RESULTADOS E DISCUSSÃO}

O projeto intitulado "Conservação Ambiental: um ato de amor" apresentou logo no momento inicial aos alunos das turmas de $2^{\circ}$ e $3^{\circ}$ ano do curso Técnico de Farmácia a justificativa do projeto, assim como problemáticas e objetivos, levando-os sempre a pensarem a respeito da relevância do estudo.

Figura 1 Exposição de conteúdos referentes a temática do projeto. Fonte: Própria

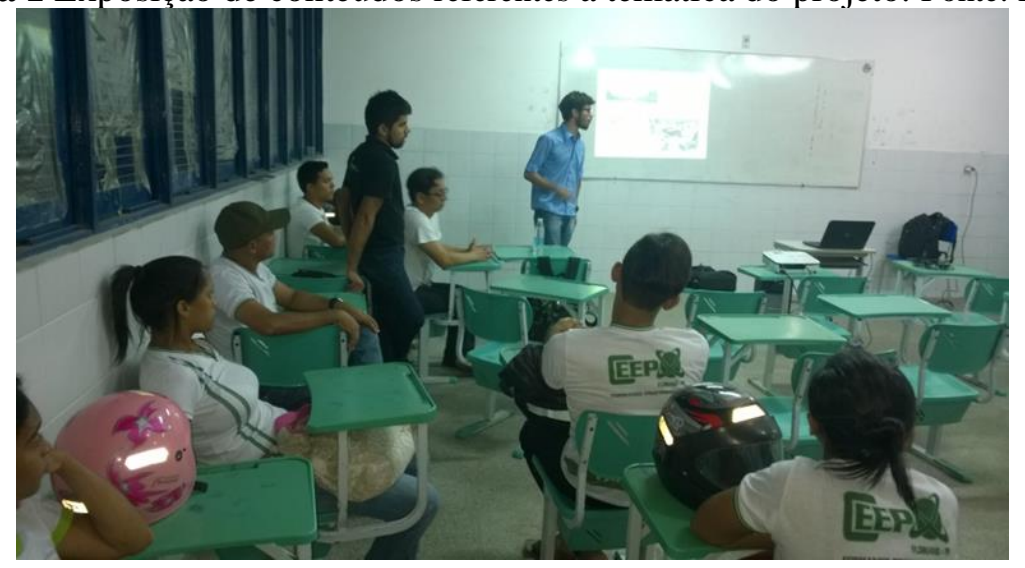


E para início de discussão os alunos foram questionados sobre os seus prévios conhecimentos a respeito da conservação ambiental, o que já haviam visto na escola e até mesmo nos meios de comunicação que estão presentes no cotidiano. E o que se percebeu foi que grande maioria confundia os termos preservação ambiental e conservação ambiental. $\mathrm{O}$ aluno-07 em sua resposta diz que "a conservação ambiental está ligada com o isolamento de regiões onde há uma variedade de espécies ameaçadas de extinção” e que cuidado não refletia em resultados expressivos. A conservação ambiental faz referência ao manejo dos recursos da natureza, garantindo qualidade de vida, e o menor impacto possível no ambiente (TEIXIERA et al., 2018). O aluno-16 surpreendeu ao mostrar certo domínio a respeito da conservação ambiental, em resposta mostra conhecimentos que ajudaram a enriquecer a discussão:

\begin{abstract}
A conservação ambiental nada mais é do que uma corrente que defende o uso consciente dos recursos que temos disponíveis, para que isso aconteça não se pode deixar também de preservar, pois, ambas as coisas estão interligadas e juntas só colaboram para que a natureza não sofra mais com nossas ações, desse modo, penso que a necessidade em conservar é ainda mais urgente hoje do que a 40 anos atrás (Aluno-16).
\end{abstract}

Os demais alunos tiveram respostas parecidas e ao que parece seguiram motivados pelo senso comum em suas respostas. $\mathrm{O}$ aluno-13 afirma que, "a conservação ambiental são práticas assumidas pela sociedade para preservação do meio ambiente”. A respeito do seu papel na conservação ambiental, usando de forma consciente os recursos naturais, os alunos responderam da seguinte forma:

Figura 2. Consciência Ambiental, nível de participação na conservação de recursos naturais. Fonte: Própria 


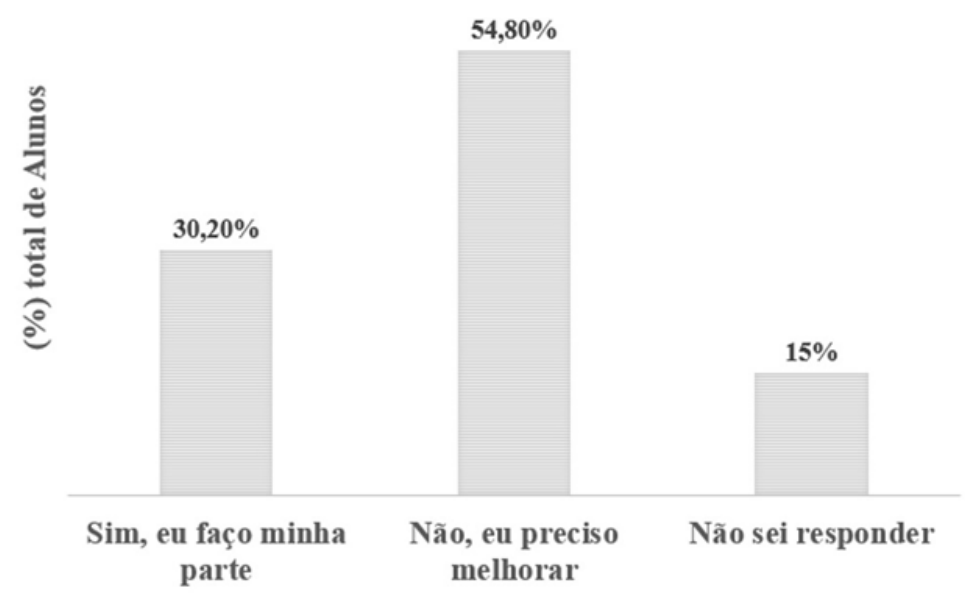

Os alunos em sua maioria reconhecem que até então não estão agindo de forma ativa em prol da conservação ambiental, 54,8\% afirmam que precisam melhorar com relação à este aspecto, 30,2\% dos alunos diz que vem fazendo a sua parte, contribuindo assim para a garantia de um ambiente com melhores condições de vida, e $15 \%$ não souberam responder à pergunta, tendo dúvidas sobre qual é de fato o seu papel nesse processo. E mesmo sendo a minoria, esse grupo demonstra o quanto o tema é insuficientemente abordado no âmbito escolar. O desenvolvimento humano levou a criação de grandes centros urbanos, e a cada dia as pessoas vem trazendo demandas relacionadas a diversas questões, trabalho, acesso a saúde, educação e etc., esquecendo-se dos cuidados que se deve ter com o meio ambiente (HENSEL, 2016).

Sobre os possíveis efeitos do descuido com a natureza, questionaram-se aos os alunos o que enxergavam na sua rotina que poderia ser originado pela falta de conservação? As respostas tiveram de modo geral grande semelhança quanto a questões climáticas, em especial, o aluno-02 relatou que percebe que em sua cidade "o calor cada vez é maior, $e$ começa mais cedo e mesmo em tempos chuvosos é possivel sentir aquele clima abafado". Assim como o aluno-09 que se lembrou das temperaturas sempre elevadas e também falou que "a cidade tem sido limpa com mais frequência, mas é possível constatar que ainda existe uma carência enorme de saneamento básico, vemos sempre poças de água cheias de insetos, podendo propagar diversas doenças”. O aluno-05 relatou da poluição no Rio Parnaíba, que recebe lixo, esgotos, e tem suas margens desmatadas. As queimadas são práticas presentes na cultura florianense, segundo os alunos-07/13 as queimadas são prejudiciais à saúde e contribui para o aumento da temperatura, diminuindo assim a qualidade de vida. As queimadas com a finalidade de limpeza surgiram a muito tempo e mesmo com a percepção dos prejuízos 
causados, essa ainda é uma pratica recorrente tanto nos ambientes rurais quanto urbanos (RIBEIRO; ASSUNÇÃO, 2002).

Ressaltaram-se ainda no questionário, possíveis ações a serem adotadas e de acordo com a concepção dos alunos, investigou-se: Que ações considerariam viáveis como propostas de intervenção para a conservação ambiental no município onde residem. Ficou evidente ao termino do projeto que os alunos adquiriram um pensamento reflexivo, apostos para o caminho certo, onde ele se enxerga como um membro da sociedade que pode contribuir de maneira satisfatória, $\mathrm{O}$ aluno-21 elaborou uma proposta que caberia muito bem em ambientes de produção industrial, já que as mesmas causam tanto impacto no meio ambiente, para ele:

\begin{abstract}
As empresas deveriam ser rigorosamente observadas de perto por um órgão responsável, respondendo a um sistema de pontos, quanto mais lixo essa empresa gera, menor pontuação ela terá ao fim do ano, e quanto maior for a consciência sustentável, maior será o reconhecimento dessa empresa na sociedade, recebendo uma pontuação positiva, que poderá dar prêmios pela contribuição da mesma com o meio ambiente.
\end{abstract}

Esse questionamento permitiu que todos os alunos pudessem opinar, proporcionando a dinâmica em grupo e possibilitando ainda a troca de conhecimentos, o que deu a ideia para uma posterior oficina sobre o tema. Outros alunos contribuíram de maneira bastante expressiva, como no caso do aluno-09 que volta a trazer seus conhecimentos para a discussão, segundo o discente: "a consciência ambiental talvez seja o maior desafio deste século, e a certeza de que muito tempo vai ser investido para sensibilizar a todos. As práticas da sociedade tem mostrado o quanto terríveis podemos ser, entendo que mesmo cumprindo meu papel, os problemas ambientais ainda vão estar ai, então é impossível impor algumas medidas, esperando que todos sigam à risca e tudo se resolva”. O meio ambiente é uma entidade forte, mas que não está livre do poder destrutivo do ser humano, até entendermos o que estamos fazendo aqui, o tempo poderá já ter se esgotado (KLOETZEL, 2017).

\title{
CONCLUSÕES
}

Com o desenvolvimento do projeto notou-se a importância de levar ao ambiente de sala de aula temas que estão sendo discutidos na sociedade, na maioria das vezes esses temas passam despercebidos pelos alunos simplesmente pelo fato dos mesmos não terem conhecimento sobre os mesmos. Percebeu-se ainda que a participação dos alunos mais jovens é indispensável, pois os impactos das ações de hoje, serão sentidas de maneira mais severa daqui a alguns anos, nessa perspectiva os alunos se tornaram então donos dos seus destinos, 
por serem indivíduos dotados de consciência, eles têm a obrigação de decidir aonde e como querem viver daqui a alguns anos, e isso só é possível por meio de uma postura ativa, tornando o ambiente mais saudável, usufruindo de forma consciente, preservando para que todos possam ter a oportunidade de viver bem.

Entende-se que a interdisciplinaridade só contribuiu para o sucesso do projeto, pois no decorrer de seu desenvolvimento, notou-se que a metodologia adotada favoreceu a assimilação dos alunos, assim como oportunizou o dinamismo e participação de todos. O que mostra o quão carente ainda são as instituições de ensino público, e o professor percebendo tais deficiências no ensino deve assumir para si a responsabilidade e buscar trazer para as aulas assuntos que podem não compor a grade curricular, mas que são essenciais para a vida em sociedade. Considera-se que os alunos participantes conseguiram extrair o máximo de aprendizado, tornando-se assim, indivíduos que refletem também no coletivo, e que tendo acesso a tamanha quantidade de informações podem se tornar seres humanos melhores.

\section{REFERÊNCIAS}

ABRAMOVAY, R. Reduzir a desigualdade entre os indivíduos para combater o aquecimento global. Boletim da Sociedade Brasileira de Economia Ecológica-Edição Especial, n. 23/24, p. 12-15, 2018.

BENEVIDES, M.; ALMEIDA, L. Desmatamento no Brasil: uma controvérsia em 50 tons de verde. Sustentabilidade em Debate, v. 6, n. 3, p. 182-213, 2015.

CARVALHO, I. C. M. Educação ambiental: a formação do sujeito ecológico. Cortez Editora, 2017.

CARVALHO, I. - "As transformações da cultura e o debate ecológico: desafios políticos para uma educação ambiental', in Tendências da Educação Ambiental Brasileira. Sta. Cruz do Sul: EDUNISC, 2001, (113-126).

CAMPOS JUNIOR, R. A. O conflito entre o direito de propriedade e o meio ambiente - e a questão da indenização das áreas de preservação florestal. Curitiba: Juruá, 2002.

DELUIZ, N.; NOVICKI, V. Trabalho, meio ambiente e desenvolvimento sustentável: implicações para uma proposta de formação crítica. Boletim Técnico do SENAC, v. 30, n. 2, p. 18-29, 2018.

DUARTE, J. L. Influência da variabilidade climática e das alterações ambientais na ocorrência de doenças sensíveis ao clima em uma capital da Amazônia Ocidental brasileira. 2017. Tese de Doutorado. Universidade de São Paulo.

GORNI, P. M. et al. Consciência ambiental e sua influência sobre o comportamento de compra com vistas à preocupação ambiental. Contextus-Revista Contemporânea de Economia e Gestão, v. 14, n. 1, p. 7-31, 2016.

HENSEL, A. R. Sustentabilidade urbana, direito urbanístico e a educação ambiental. In: BÜHRING, M. A. Função socioambiental da propriedade. Caxias do Sul, RS: Educs, 2016. p. $39-54$.

JACOBI, P. Meio ambiente e sustentabilidade. Revista de Desenvolvimento e Meio, 1999. KLOETZEL, K. O que é meio ambiente. Brasiliense, 2017. 
RIBEIRO, M. S.; MARTINS, E. A informação como instrumento de contribuição da contabilidade para a compatibilização no desenvolvimento econômico e a preservação do meio ambiente. Caderno de Estudos, n. 9, p. 01-13, 1993.

RIBEIRO, H.; ASSUNÇÃO, J. V. de. Efeito das queimadas na saúde humana. Estudos Avançados, v. 16, n. 44, p. 125-148, 2002.

SACHS, I. - "Do Crescimento Econômico ao Ecodesenvolvimento", in Desenvolvimento e Meio Ambiente no Brasil: a contribuição de Ignacy Sachs. Porto Alegre: Pallotti; Florianópolis: APED, 1998 (161- 163)

SARLET, I. W. A eficácia dos direitos fundamentais: uma teoria geral dos direitos fundamentais na perspectiva constitucional. Livraria do Advogado Editora, 2018.

SILVA, I. A. S.; BARROS, J. R. DEGRADAÇÃO AMBIENTAL, COBERTURA E USO DAS TERRAS-UMA ANÁLISE GEOGRÁFICA DO MUNICÍPIO DE GILBUÉS-PI. REVISTA EQUADOR, v. 5, n. 2, p. 190-204, 2016.

TEIXEIRA, N. F. F.; MOURA, P. E. F.; SILVA, E. V. Educação Ambiental em paisagem cárstica para o desenvolvimento do turismo sertanejo no semiárido cearense. Revista Brasileira de Educação Ambiental (RevBEA), v. 13, n. 1, p. 262-271, 2018.

VENTURA, A. C.; ANDRADE, J. C. S.; DE ALMEIDA, A. C. A. Soluções locais para problemas globais: análise de possíveis contribuições das tecnologias sociais para a mitigação do aquecimento global. Revista Ciências Administrativas ou Journal of Administrative Sciences, v. 17, n. 3, 2014.

ZANETI, I. C. B. B.; SÁ, L. M. A educação ambiental como instrumento de mudança na concepção de gestão dos resíduos sólidos domiciliares e na preservação do meio ambiente.

ENCONTRO DA ASSOCIAÇÃO NACIONAL DE PÓS-GRADUAÇÃO E PESQUISA EM AMBIENTE E SOCIEDADE1, 2002. 